\title{
Survival to prescribed fire of plantation-grown Corsican black pine in northern Portugal
}

\author{
Paulo M. Fernandes • Manuel M. Fernandes • \\ Carlos Loureiro
}

Received: 24 January 2012 / Accepted: 9 April 2012 /Published online: 8 May 2012

(C) INRA / Springer-Verlag France 2012

\begin{abstract}
- Context The current fire regime threatens black pine (Pinus nigra Arn.) persistence in the Mediterranean Basin, which recommends larger-scale fuel treatments. Prescribed burning is an option for stand protection but its use in young stands (which are particularly at risk) is hindered by the scarce knowledge on post-fire tree survival.

- Aims The objectives were to characterize bark thickness as a fire-resistance trait in P. nigra and to describe how postfire tree survival responds to tree size and fire effects in a 16-year-old plantation.

- Methods Bark thickness was related to diameter at breast height and height in the stem. Metrics describing tree size and stem and crown damage were measured 1 year after prescribed burning in 259 trees. Tree survival was modeled with logistic regression and Classification and Regression Tree analysis.

- Results Bark thickness increased linearly with diameter at breast height $(\mathrm{dbh})$ and decreased with height in the stem. Tree survival was primarily a function of crown injury. Stem damage was an influent factor in small trees.
\end{abstract}

Handling Editor: Eric Rigolot

Contribution of the co-authors Paulo M. Fernandes supervised work, contributed to sampling design and data analysis, and wrote the paper. Manuel M. Miranda carried out data analysis. Carlos Loureiro assisted in sampling design. All authors were involved in data collection.

P. M. Fernandes $(\bowtie) \cdot$ M. M. Fernandes $\cdot$ C. Loureiro Departamento de Ciências Florestais e Arquitetura Paisagista, Centro de Investigação e de Tecnologias Agro-Ambientais e Biológicas (CITAB),

Universidade de Trás-os-Montes e Alto Douro,

Apartado 1013,

Vila Real 5001-801, Portugal

e-mail: pfern@utad.pt
- Conclusion Due to thinner bark and lower tolerance to crown damage, young $P$. nigra trees are less fire-resistant than other Mediterranean pines, e.g., Pinus pinaster. Prescribed fire should not be attempted if dbh $<10 \mathrm{~cm}$. Mechanical clearing is the treatment of choice in young stands with a significant shrub layer.

Keywords Post-fire survival · Bark thickness · Fire resistance $\cdot$ Pinus nigra $\cdot$ Prescribed burning

\section{Introduction}

Black pine (Pinus nigra Arn.) is a widespread montane pine of the Mediterranean Basin. P. nigra does not have reproductive adaptations to fire, i.e., early flowering and serotinous cones (Tapias et al. 2004), implying that its persistence relies on seed sources provided by individuals surviving the fire or located outside the burned area. After large and intense fires, $P$. nigra survival and seedling density are very low (Rodrigo et al. 2004), to which short-distance seed dispersal contributes (Ordóñez et al. 2006; Arianoutsou et al. 2010). As fire events become more severe, the postfire regeneration of $P$. nigra forests is increasingly difficult, and the likelihood of replacement by other vegetation types is very high (Pausas et al. 2008; Retana et al. 2012).

P. nigra has a long life span and mature trees are tall and have thick bark, large buds and dense wood, forming natural stands with open canopy, elevated crown base and low accumulation of surface fuel (Tapias et al. 2004; Fulé et al. 2008). These traits are consistent with a fire-resistance strategy and a stand-thinning fire regime (Keeley and Zedler 1998), which is supported by the findings of multicentennial fire history studies in Spain (Fulé et al. 2008) and Greece (Touchan et al. 2012). Quantitative information on the 
postfire mortality of $P$. nigra is extremely scarce. Ordóñez et al. (2005) report that $P$. nigra survival after a large wildfire in NE Spain decreased with crown damage and increased with tree size. González et al. (2007) used National forest inventory plots in the same region to determine mean postfire survival percentages (tree and stand levels). Fernandes et al. (2008) combined morphological traits data and fire modeling to classify P. nigra in between the more fireresistant European pine species (Pinus pinea, Pinus pinaster) and those less resistant to fire (Pinus halepensis and Pinus uncinata). This assessment was confirmed by Pimont et al. (2011), who developed the first model of fire-induced mortality for the species from data collected in an old-growth stand in Corsica, France.

Concerns with the persistence of $P$. nigra forests under the current and future fire regime are a constant in the literature. The vulnerability to fire of most $P$. nigra stands is blamed on high plantation density and fire suppression (Tapias et al. 2001; Fulé et al. 2008; Pausas et al. 2008). Fuel treatments, including prescribed burning and similarly to other Mediterranean pines (e.g., Fernandes 2009), have been proposed to increase the resistance of $P$. nigra stands to wildfire (Fulé et al. 2008; Pimont et al. 2011). Reliable estimation of post-fire tree mortality is crucial to plan prescribed burning and to support decision on a variety of management activities, namely salvage logging and reforestation (Hood et al. 2010). The post-fire fate of conifers is mainly determined by the extent of fire-inflicted damage as determined by interactions between tree morphology and fire behavior characteristics (Peterson and Ryan 1986). Tree death can result from injury to the crown, stem and roots, but most studies agree that foliage and bud kill play the major role (e.g., Sieg et al. 2006). However, stem damage is an important determinant of small tree death (van Mantgem and Schwarz 2004) and is often considered in fire-caused mortality models (e.g., Ryan and Reinhardt 1988). Stem damage caused by prescribed burning operations is not a significant concern for medium-sized European pines, regardless of species, but more data is needed for smaller individuals of relatively thin-barked species (Fernandes et al. 2008).

In 2005, a 3-ha area of a Corsican black pine (P. nigra subsp. salzmannii var. corsicana) young plantation was prescribed burnt as part of a fuel break within a landscape-scale fuel management project in northern Portugal. Tree survival was a minor concern, hence providing an opportunity to assess the resistance of small-sized P. nigra individuals to fire. Guidance to prescribed burning operations in P. nigra stands needs specific empirical data to identify fire-caused thresholds for tree mortality. Our objectives were to (1) characterize bark thickness and (2) explain post-fire tree survival through tree size and fire effects metrics. We expected that the combined effect and interaction between stem and crown injury would determine either tree death or tree survival.

\section{Materials and methods}

\subsection{Study site}

The study site is located in the Marão mountain range at $41^{\circ}$ $16^{\prime} 21^{\prime \prime} \mathrm{N}, 7^{\circ} 54^{\prime} 53^{\prime \prime} \mathrm{W}$ in an eastern-oriented steep slope (40\%). Elevation ranges from 1,140 to $1,195 \mathrm{~m}$. Stand age and density of the $P$. nigra stand were respectively 16 years and $1,400 \mathrm{ha}^{-1}$, and trees were planted in rows and unprunned. Understorey ground cover was almost total with a 0.8 m mean height, and was dominated by the shrubs Pterospartium tridentatum, Erica umbellatta, and Erica australis. The prescribed fires were carried out by the Forest Service in 12-13 December 2005 and proceeded downslope and against the wind under very mild fire weather (FWI of the Canadian Forest Fire Weather Index System=1). Surface wind speed and ambient temperature varied in the ranges of $5-15 \mathrm{~km} \mathrm{~h}^{-1}$ and $5-8^{\circ} \mathrm{C}$. Fireline intensities in the $100-300 \mathrm{~kW} \mathrm{~m}^{-1}$ range were prevalent, as estimated from photographs taken during the fires and equations relating flame size and fire intensity (Fernandes et al. 2009).

\subsection{Data collection and processing}

Fieldwork was carried out in January 2007, ca. 1 year after the fire. We measured the diameter at breast height (dbh; $1.3 \mathrm{~m}$ ) and corresponding bark thickness (BT) in 50 trees in unburnt areas of the stand; in 30 trees within the treated area that had no char at $1.3 \mathrm{~m}$; and in 40 trees in a nearby 48 year-old stand to expand the tree size range. Additionally, 20 of the untreated stand trees were the subject of bark thickness and diameter measurement at heights of $0.1,0.5$, and $0.9 \mathrm{~m}$ to describe variation along the stem profile. Normalized bark thickness, the ratio of bark thickness to stem radius (NBT), was computed to express how the relative importance of bark changes with height in the stem. In all cases, the assessed bark thickness was the average of two measurements to the nearest $\mathrm{mm}$ on the uphill and downhill sides of the tree, using a standard bark gauge.

Considering the fairly homogeneous fuel complex and steady burning conditions, we assumed that tree damage by fire would vary primarily with tree size. Metrics describing tree size and injury were assessed in 240 trees equally distributed by the 5 and $10 \mathrm{~cm}$ dbh classes. All trees with $\mathrm{dbh} \geq 12.5 \mathrm{~cm}(n=19)$ within the burn area were additionally sampled to expand the study's scope. We did not include trees on the edge of the prescribed burnt area, and conservatively avoided live trees with poor crown vitality that could die in the short term.

Table 1 lists the tree size and fire effects metrics, measured or derived from measurements, with calculations explained. Root or basal injury was ruled out as possible causes of tree death, as duff consumption was negligible due 
Table 1 Measured and calculated descriptors of tree size and fire effects

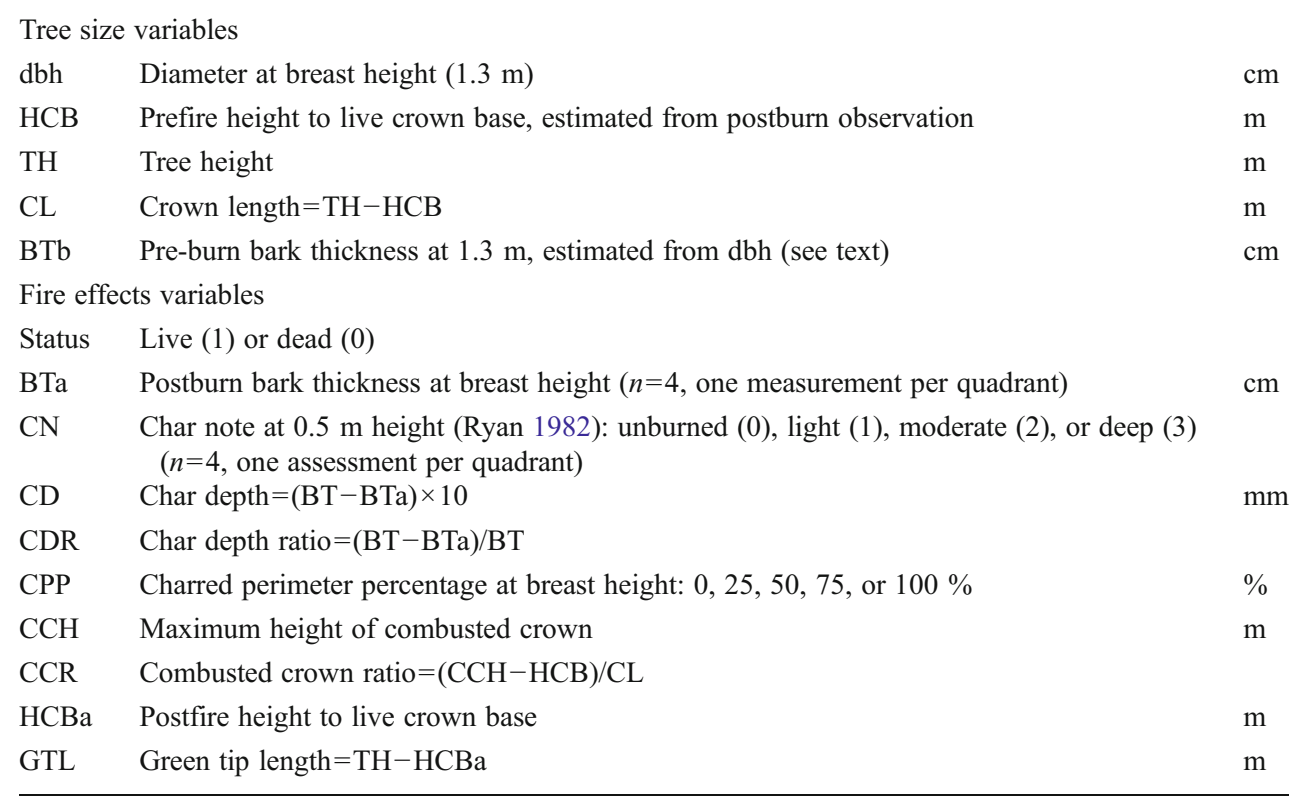

to its high moisture content. As expected, evidence of crown scorch was no longer available 1 year after the fire. The shrub layer was the main fire-spread vector, and there were no gaps between the understorey and the overstorey. Hence, all trees suffered foliar combustion to some degree. The maximum height of combusted crown usually occurred on the leewardside of the tree due to downslope fire spread, and was measured as a descriptor of crown injury and proxy for flame height. Stem-char height is the widely used alternative to crown combustion height but was disregarded because its upper limits were not always easy to identify due to the dark gray color of P. nigra bark. Heights on trees were measured with a tape (to the nearest centimeter) up to a height of $2.5 \mathrm{~m}$, and above that with a laser hypsometer (to the nearest $0.1 \mathrm{~m}$ ).

Fire-caused stem injury, contrarily to foliar necrosis, is not detectable by external observation (Hood et al. 2008). Given the study focus, we endeavored to collect as much nondestructive information as possible on potential cambium damage, comprising morphological variables (dbh, bark thickness) and descriptors of the depth and perimetral extent of charred bark (Table 1). The depth of bark char was categorized as per Ryan (1982), and also quantified as the difference between preburn and postburn bark thicknesses; the former was estimated from dbh (see the "Section 2.3"). Post-burn assessments made at the quadrant level $(n=4)$ were averaged. Combustion height, char depth, and charred perimeter were expressed in relative terms (see Table 1).

\subsection{Data analysis}

All statistical tests adopted the significance level of $\alpha=0.05$. Bark thickness was fitted to dbh through least squares regression. For each height level in the stem, we summarized bark thickness and normalized bark thickness. Linear mixed regression (with tree as the random variable) was used to model bark thickness from height in the stem and stem diameter, the two fixed effects. The Tukey-Kramer honestly significant difference criterion was used to test whether height level affected the two bark thickness variables.

We modeled the likelihood of individual tree survival to fire with binomial logistic regression. Dbh and preburn bark thickness were squared to reflect the time required to cause cambium necrosis (Peterson and Ryan 1986), and were considered as candidates for model inclusion in addition to the variables in Table 1. The independent variables with a significant effect on tree status (dead $=0$, live $=1)$ were identified with the Wald $\chi^{2}$ statistic. Models were developed by adding the predictor variables one at a time, until none of the remaining variables could significantly decrease residual deviance. Potential multicollinearity problems between independent variables were checked by computing variance inflation factors. Model coefficients were estimated by maximum likelihood and overall model significance was evaluated by the likelihood ratio test. Model performance was assessed by the area under the receiver operating characteristic curve (AUC), and by agreement rates between the observed and predicted tree status.

Classification and Regression Tree (CART) analysis uses recursive partitioning to reveal data structuring, interactions between variables and discrimination rules, and was used to complement the logistic regression results. The splitting process stopped when goodness of fit was optimized, as measured by the Akaike Information Criterion corrected for finite sample sizes (AICc). 


\section{Results}

\subsection{Bark thickness}

Tree dbh and breast height bark thickness varied respectively in the ranges of 2.0-47.7 and $0.1-3.2 \mathrm{~cm}$, with NBT= $0.130 \pm 0.037$; the maximum dbh and bark thickness values in the 16-year-old stand were 16.5 and $1.5 \mathrm{~cm}$. The relationship between the two variables in the young stand was best described by an equation of the form $\left(n=80, r^{2}=0.82\right)$ :

$\mathrm{BT}=a \mathrm{dbh}^{\mathrm{b}}$

where, $a=0.037 \pm 0.007$ and $b=1.274 \pm 0.081$, with a confidence interval of 1.12-1.44 for the exponent. However, no evidence of nonlinearity was found over the entire range of data $(b=1.012)$ and the following equation was fitted $(n=$ $\left.120, r^{2}=0.93\right)$ :

$\mathrm{BT}=-0.029+0.070 \mathrm{dbh}$

with standard errors of 0.031 and 0.002 for the regression coefficients. Equation 2 tends to overestimate the smallest individuals BT in the 16-year-old stand, conversely producing underestimates in the upper range of tree size (Fig. 1).

Bark depth decreased with height in the tree trunk (Table 2). This decline was not just the consequence of a decrease in stem diameter with height, as both diameter $(p<0.0001)$ and height level $(p<0.0001)$ contributed to explain the variation in bark thickness $\left(r^{2}=0.94\right)$. Likewise, normalized bark thickness decreased significantly $(p<0.0001)$ with height in the stem (Fig. 2).

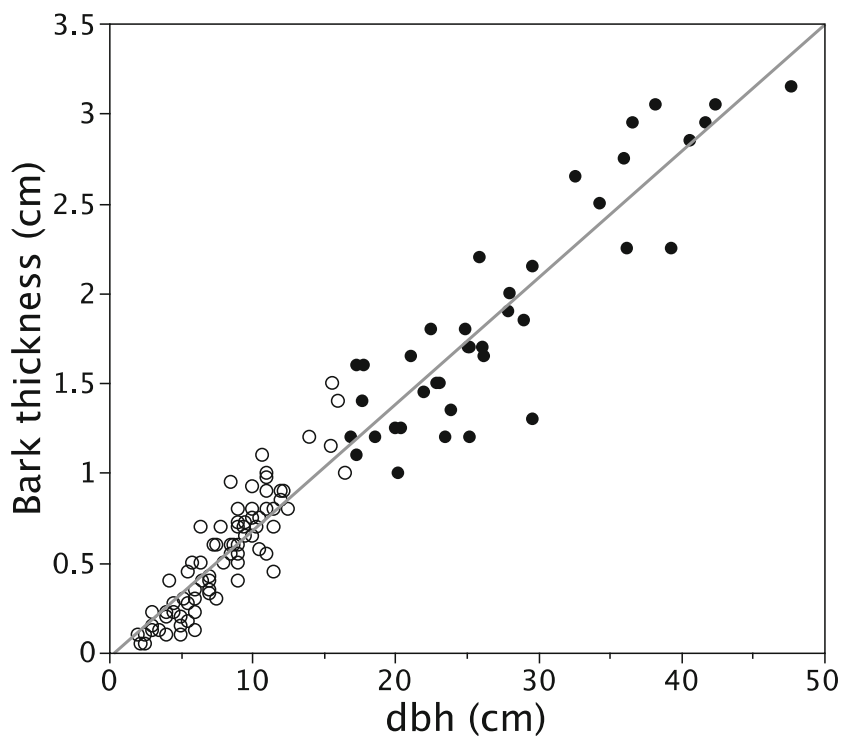

Fig. 1 Relationship between breast-height bark thickness and stem diameter, with Eq. 2 fitted. Empty circle 16-year-old stand, filled circle 48-year-old stand
Table 2 Bark thickness (centimeter) along the stem profile ( $n=20$ per height level) with least square means (LSM) after controlling for the effect of stem diameter

\begin{tabular}{lcc}
\hline Height level $(\mathrm{cm})$ & Mean \pm SE & LSM \\
\hline 10 & $1.9 \pm 0.1$ & $1.6 \mathrm{a}$ \\
50 & $1.4 \pm 0.1$ & $1.3 \mathrm{~b}$ \\
90 & $1.1 \pm 0.1$ & $1.2 \mathrm{~b}$ \\
130 & $0.7 \pm 0.1$ & $0.9 \mathrm{c}$ \\
\hline
\end{tabular}

LSM followed by the same letter are not significantly different ( $p>$ 0.05 , Tukey-Kramer honestly significant difference test)

\subsection{Tree survival to fire}

Table 3 displays the means for morphological and fire effects metrics by tree condition, either measured or computed, and including bark thickness from Eq. 1. All variables but one (char depth, not in Table 3) was significantly different between live and dead trees, the former being larger and less impacted by fire. Surviving trees had a mean $2.3 \mathrm{~m}$ green tip (range, $0.6-7.0 \mathrm{~m}$ ), corresponding to a 0.55 fraction (range, 0.21-0.95) of the preburn crown length. Postfire height to live crown base and height of crown combustion were correlated $(r=0.45, p<0.0001)$, with a mean 2.4:1 ratio. Combusted crown ratio (CCR) was the single most relevant predictor of tree survival $\left(\chi^{2}=83.6\right)$, followed by the correlates and estimate of bark depth $\left(\chi^{2}\right.$ in the range of 45.7-46.6), and the breast height percentage of charred perimeter CPP $\left(\chi^{2}=43.4\right)$. CPP was correlated with the three char depth metrics $(p<0.0001)$.

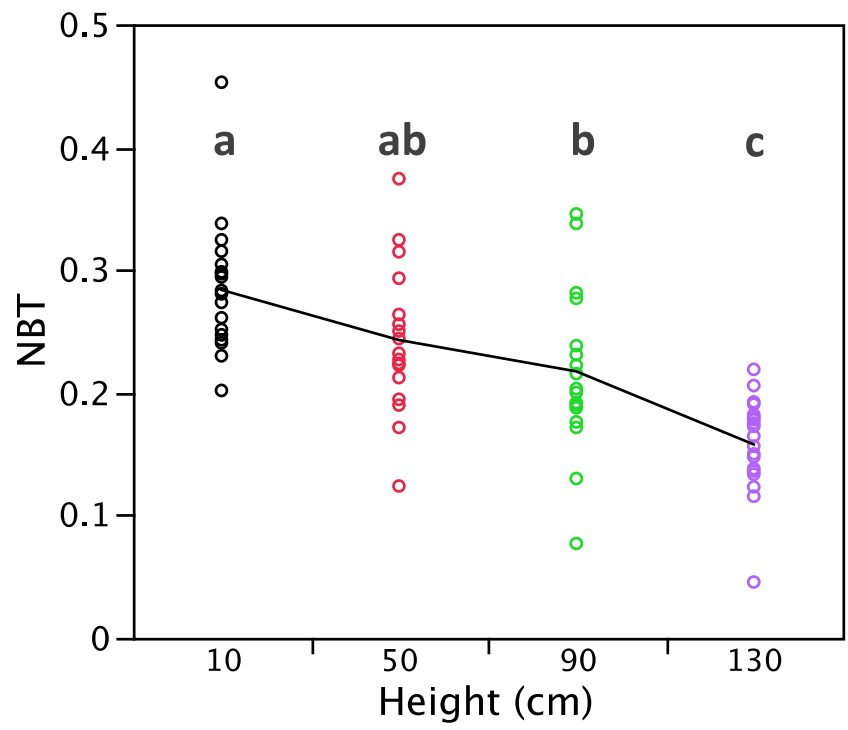

Fig. 2 Normalized bark thickness in relation to height above ground. The line connects mean values. Means followed by the same letter are not significantly different ( $p>0.05$, Tukey-Kramer honestly significant difference test) 
Table 3 Mean \pm standard error and range of selected variables for $P$. nigra dead $(0, n=123)$ and live $(1, n=136)$ individuals 1 year postfire

\begin{tabular}{lll}
\hline Variable & 0 & 1 \\
\hline dbh & $6.8 \pm 2.7$ & $9.2 \pm 2.9$ \\
& $2.0-15.0$ & $3.0-16.0$ \\
TH & $4.0 \pm 1.2$ & $5.0 \pm 1.6$ \\
& $1.8-7.6$ & $1.9-13.1$ \\
BT & $0.4 \pm 0.2$ & $0.6 \pm 0.2$ \\
& $0.1-1.1$ & $0.1-1.2$ \\
CN & $1.9 \pm 0.3$ & $1.7 \pm 0.5$ \\
& $0.3-2.0$ & $0.0-2.0$ \\
CDR & $0.3 \pm 0.3$ & $0.2 \pm 0.2$ \\
& $0.0-1.0$ & $0.0-0.7$ \\
CPP & $73.2 \pm 25.4$ & $46.9 \pm 34.9$ \\
& $0-100$ & $0-100$ \\
CCH & $1.7 \pm 0.5$ & $1.3 \pm 0.4$ \\
& $0.9-4.0$ & $0.8-2.3$ \\
CCR & $0.3 \pm 0.2$ & $0.1 \pm 0.1$ \\
& $0.0-0.6$ & $0.0-0.4$ \\
\hline
\end{tabular}

All means are significantly different $(p<0.05)$ between tree statuses

See Table 1 for the explanation of the symbols for the variables

The multivariate logistic model for the probability of $P$. nigra survival to fire is presented in Table 4 , with dbh, CCR and CPP as independent variables. Neither the estimated BT nor $\mathrm{BT}^{2}$ (or $\mathrm{dbh}^{2}$ ) were superior to $\mathrm{dbh}$, and none of the descriptors of bark consumption further decreased deviance. The three-variable model has the lowest AICc value when compared with single- and two-variable alternative models. Correlations between CCR and dbh $(r=-0.22)$ and between CPP and CCR $(r=0.43)$ were significant $(p<0.05)$ but did not imply multicollinearity, as maximum variance inflation factors were very low $(<2)$. Overall model accuracy is $81.8 \%$, with $20.3 \%$ of the observed dead trees predicted to be alive and $16.2 \%$ of live trees predicted to be dead. Figure 3 exemplifies model output and how the two dominant variables (CCR and dbh) interact to determine survival likelihood.

The classification tree in Fig. 4 is equivalent to the logistic regression both in performance $(\mathrm{AUC}=0.88)$ and in the independent variables it uses. Tree survival was generalized when the vertical extent of burned crown was less than $23 \%$ of its length and either dbh exceeded $10 \mathrm{~cm}$, or was lower than $10 \mathrm{~cm}$ but breast height char was not present in more than $50 \%$ of the stem circumference. Most

Table 4 Logistic regression model coefficients \pm standard errors for the first year probability of $P$. nigra survival to fire $\left(\chi^{2}=140.7, p<0.0001\right.$, $\mathrm{AUC}=0.87$ )

\begin{tabular}{llll}
\hline Intercept & $\mathrm{dbh}$ & $\mathrm{CPP}$ & $\mathrm{CCR}$ \\
\hline $0.363 \pm 0.566$ & $-0.422 \pm 0.072$ & $0.026 \pm 0.006$ & $7.924 \pm 1.640$
\end{tabular}

All independent variables are significant at $p<0.0001$

See Table 1 for the explanation of the symbols for the independent variables.

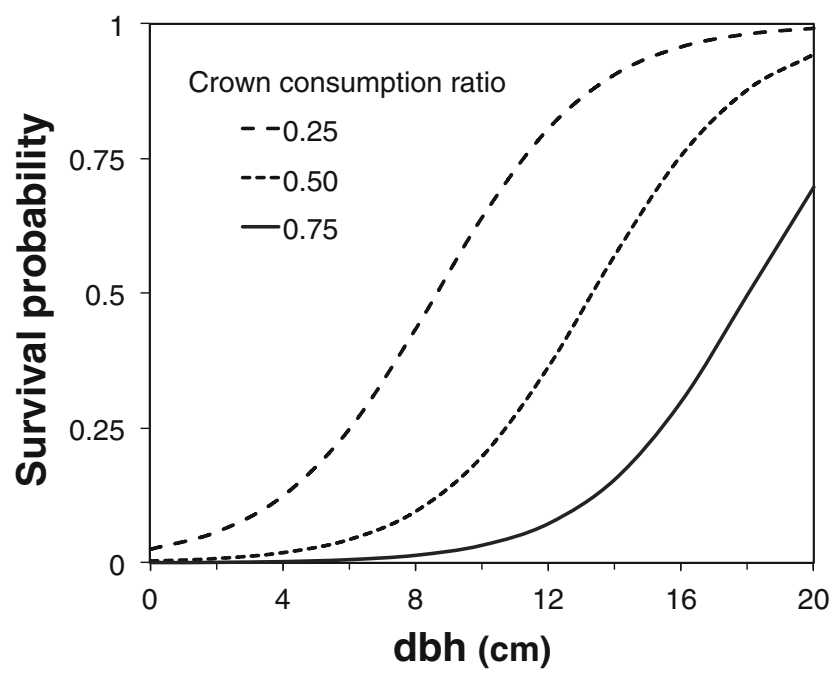

Fig. 3 Probability of P. nigra post-fire survival as per Table 4 model, with $\mathrm{CPP}=50 \%$

trees with dbh $<6 \mathrm{~cm}$ (BT $<0.4 \mathrm{~cm}$, Fig. 2) did not survive, as well as all trees with $\mathrm{CCR} \geq 0.39$. CCR, dbh, and CPP account for $59.5,26.5$, and $14.0 \%$, respectively, of variation explained, which corresponds to percentages of 59.5 and $40.5 \%$ for crown kill and cambium kill, respectively; these percentages change to 56.7 and $43.3 \%$ if the CART analysis splitting process is repeated until the AICc is minimized, which adds char depth ratio as an explaining variable when $0.23<\mathrm{CCR}<0.39$.

\section{Discussion}

\subsection{Bark thickness}

Thicker bark provides better insulation from fire temperatures (Peterson and Ryan 1986). P. nigra has been previously (Fernandes et al. 2008) ranked in between other montane pines ( $P$. sylvestris and $P$. uncinata) and lowelevation Mediterranean pines (P. pinaster, P. pinea, and $P$.

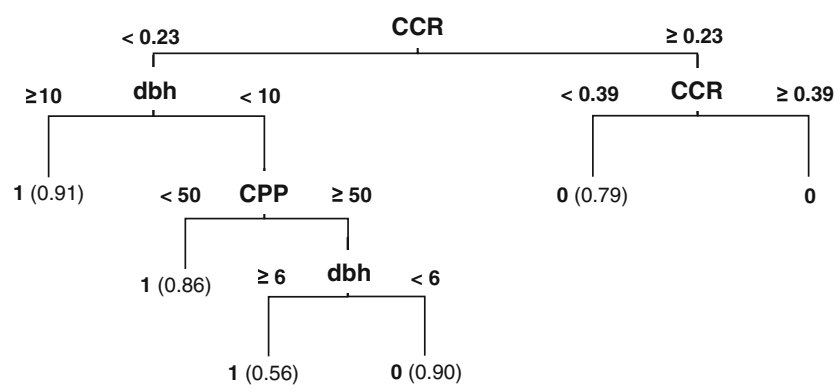

Fig. 4 Classification tree of $P$. nigra survival to fire; $1=$ surviving trees, $0=$ dead trees. The proportion of trees that survive or die is indicated in brackets whenever the separation is incomplete 
halepensis) in regards to normalized bark thickness, which describes relative fire resistance better than bark thickness alone. Mean NBT $=0.13$ for this study trees, i.e., halfway the values of 0.09 and 0.18 resulting from the BT equation in Pimont et al. (2011) and in Fernandes et al. (2008), respectively. Data in Ordóñez et al. (2005) indicates higher NBT (0.2-0.3) for P. nigra in NE Spain.

Stem death caused by flaming combustion is limited to BT $\leq 2.5 \mathrm{~cm}$ (Ryan 1998) and pines tend to attain comparable NBT at maturity (Jackson et al. 1999). Hence, differences in bark thickness among young individuals are more representative of fire-resistance differences between species. In the sampled P. nigra population, bark thickness increases linearly with $\mathrm{dbh}$, which indicates an exactly proportional investment in protection from fire as plant size increases. The findings then suggest that Corsican P. nigra did not evolve under a regime of frequent fire, unlike species that accumulate bark at disproportionately lower rates as trees grow in size (Jackson et al. 1999). Nevertheless, the vertical gradient in BT and NBT implies variation in cambium damage. Vertical variation in $\mathrm{BT}$ is more prominent in $P$. nigra than in 10- to 20-year-old $P$. pinaster and $P$. radiata trees (de Ronde 1982). Consequently, as flame size and fire intensity increase, cambium injury likelihood will increase at a higher rate in P. nigra. Bark thickness interacts with both fire intensity and flame residence time to determine the contribution of stem injury to tree mortality (Bova and Dickinson 2005).

\subsection{Tree survival to fire}

The study considered the whole range in tree dimensions and apparent burn severity observed in the experimental site. The existing heavy fuel load and vertical continuity between the understorey and the overstorey were favorable to full crown scorch and tree torching. However, the convection plume was tilted and cooled by the moderately windy and cool weather conditions, presumably mitigating the effects of fire on trees. Crown scorch height, not measured in this study, is often assumed to be a 6:1 function of flame height (Alexander and Cruz 2012). Nonetheless, the ratio of postfire live crown base height to crown combustion height was substantially lower (2.4:1 on average). Burn weather must again have contributed to this outcome, both directly (lower crown scorch height), and indirectly by decreasing the heat load on terminal buds within the scorched region. Similar to observations in other conifers (Fernandes and Rigolot 2007; Hanson and North 2009), scorched portions of the crown probably produced foliage in the year following fire, hence decreasing the height of effective crown kill; the likelihood of tree survival to fire increases with bud size, and P. nigra has the largest bud width amidst Mediterranean pines (Tapias et al. 2004).
Fire effects on P. nigra trees were a function of both tree size and fire behavior as expressed by the height of combusted crown and char-depth metrics, which respectively reflect fire intensity and residence time. As previously reported (Ordóñez et al. 2005; Pimont et al. 2011), larger individuals were more likely to withstand fire because less of their foliage was killed and their phloem and vascular cambium were better insulated. Both logistic regression (Table 4) and CART analysis (Fig. 4) indicate that survival to fire was primarily determined by damage to the crown. However, whereas logistic regression suggests that trees with high canopy damage can survive if large enough (Fig. 3), the CART shows that the dbh effect in curbing survival was restricted to CCR $<0.23$ (Fig. 4). This discrepancy is explained by the fact that trees with both $\mathrm{dbh}>12 \mathrm{~cm}$ and CCR $>0.25$ were not present in the dataset, and attests the value of supplementing logistic regression with CART analysis.

The involvement of stem damage in tree death was practically restricted to small-sized individuals ( $\mathrm{dbh}<10 \mathrm{~cm}$ or BT $<0.7 \mathrm{~cm}$, Fig. 1) when the concurrent level of crown damage was low. Variation in dbh and CPP contributed to discriminate between dead and live trees, but descriptors of absolute or relative char depth (which were correlated with CPP) did not improve the logistic regression. Although association between bark char and cambium necrosis is expected when bark is thin (Hood et al. 2008), flame residence time was low in this study and the extent of bark char was modest for most trees; only $10 \%$ of the trees exhibited a char depth ratio $\geq 0.5$, for example. Additionally, uncertainty in the estimation of char depth and char depth ratio is introduced by estimating preburn BT with Eq. 1 and by heat-caused bark swelling (Butler et al. 2005).

Crown scorch metrics describe the immediate loss of photosynthetic capacity and are common to most postfire tree mortality models (Fernandes et al. 2008; Woolley et al. 2012). Crown scorch data was not acquired in this study. This may partially explain why model performance is slightly poorer than in most studies of fire-induced tree mortality or survival, where AUC is typically $>0.9$. Lack of crown scorch data also precludes comparison of our modeling results with those obtained for other European species. Nonetheless, and despite the likely occurrence of post-burn flushing, the physiognomy of surviving $P$. nigra trees suggests less tolerance of canopy damage than the more resistant species $-P$. pinea and $P$. pinaster (Fernandes et al. 2008). Whereas $P$. pinaster individuals with the same mean size $(\mathrm{dbh}=9 \mathrm{~cm})$ still have a $50 \%$ survival chance when $90 \%$ of their crown length is scorched (Fernandes and Rigolot 2007), the average survivor in this study was characterized by $\mathrm{CCR}=0.1$ and retention of more than half of its live crown length (Table 3). Hence, P. nigra is expected to endure proportionally smaller crown damage than those 
species. P. nigra is less fire resistant than $P$. pinaster of the same age (Pimont et al. 2011), but also than P. pinaster of the same size, implying lower fire behavior thresholds for heat-inflicted injury.

This study addressed postfire first-year tree mortality. Midterm mortality following fire is possible in P. nigra (Ordóñez et al. 2005), similar to other pines and in connection with bark beetle infestation (Fernández and Salgado 1999). However, delayed postfire mortality is not expected to affect small pines (van Mantgem and Schwarz 2004). Informal inspection of the stand 4 years after burning did not reveal additional mortality. Models developed in this study are essentially descriptive, but results add to the current understanding of fire-induced mortality of small pines and relatively thin-barked pines, especially because it provides insights on the relative roles of cambium and crown kill. Future studies should assess crown scorch to allow a more direct linkage between fire characteristics and fire effects.

\subsection{Management implications}

P. nigra plantations in the Iberian Peninsula are often composed of small- to medium-sized trees (Ordóñez et al. 2005), implying high vulnerability to fire. Crown-fire likelihood is higher and survival to surface fire is presumably lower than in old-growth stands (Fulé et al. 2008; Pimont et al. 2011). Hence, while fuel treatments in P. nigra plantations are advised, our findings indicate a more limited role for prescribed burning than in more fire-resistant pines. Prescribed fire operations in young P. nigra stands will require additional caution in comparison with more fire-resistant species, e.g., P. pinaster, because of lower normalized bark thickness and higher susceptibility to crown injury. Control of fire intensity is important not just to limit upward heat release and crown scorch but because taller flames are likely to increase the likelihood of cambial injury at increasingly higher positions in the stem profile. Prolonged heating due to an excessively dry forest floor has also the potential to damage the trunk base.

Prescribed burning in young $P$. nigra stands with a welldeveloped shrub understorey is conducive to unacceptable damage, even when burning conditions are favorable, like in this study. Nevertheless, tree mortality in young stands can be minimized and prescribed burning is feasible if these conservative conditions are met: restrict underburning to $\mathrm{dbh}>10 \mathrm{~cm}$, avoid crown injury, and minimize combustion duration. Opportunities to implement burn prescriptions that comply with these requirements may be exceedingly scarce. Also, decrease in fire hazard is likely to be unsatisfactory under marginal burning conditions in denser stands with higher forest floor accumulation. Therefore, mechanical treatments are preferable if wildfire risk is high enough that it justifies early fuel control, postponing prescribed burning until trees are better protected from fire and the shrub layer is less conspicuous.

Funding This study was supported by the European Commission in the frame of the FP6 Integrated Project FIRE PARADOX (FP6018505).

\section{References}

Alexander ME, Cruz MG (2012) Interdependencies between flame length and fireline intensity in predicting crown fire initiation and crown scorch height. Int J Wildland Fire 21:95-113

Arianoutsou M, Christopoulou A, Kazanis D, Tountas T, Ganou E, Bazos I, Kokkoris Y (2010) Effects of fire on high altitude coniferous forests of Greece. In: Viegas DX (ed) Proc. VI International Conf. on Forest Fire Research. ADAI, Coimbra, CD-ROM

Bova AS, Dickinson MB (2005) Linking surface-fire behaviour, stem heating, and tissue necrosis. Can J For Res 35:814-822

Butler BW, Webb BW, Jimenez D, Reardon JA, Jones JL (2005) Thermally induced bark swelling in four North American tree species. Can J For Res 35:452-460

de Ronde C (1982) The resistance of Pinus species to fire damage. South Afr For J 122:22-27

Fernandes PM (2009) Examining fuel treatment longevity through experimental and simulated surface fire behaviour: a maritime pine case study. Can J For Res 39:2529-2535

Fernandes PM, Rigolot E (2007) The fire ecology and management of maritime pine (Pinus pinaster Ait.). For Ecol Manage 241:1-13

Fernandes PM, Vega JA, Jiménez E, Rigolot E (2008) Fire resistance of European pines. For Ecol Manage 256:246-255

Fernandes PM, Botelho HS, Rego FC, Loureiro C (2009) Empirical modelling of surface fire behaviour in maritime pine stands. Int $\mathrm{J}$ Wildland Fire 18:698-710

Fernández MF, Salgado JM (1999) Susceptibility of fire-damaged pine trees (Pinus pinaster and Pinus nigra) to attacks by Ips sexdentatus and Tomicus piniperda (Coleoptera: Scolytidae). Entomol Gener 24:105-114

Fulé PZ, Ribas M, Gutiérrez E, Vallejo R, Kaye MW (2008) Forest structure and fire history in an old Pinus nigra forest, eastern Spain. For Ecol Manage 255:1234-1242

González JR, Trasobares A, Palia M, Pukkala T (2007) Predicting stand damage and tree survival in burned forests in Catalonia (North-East Spain). Ann For Sci 64:733-742

Hanson CT, North MP (2009) Post-fire survival and flushing in three Sierra Nevada conifers with high initial crown scorch. Int J Wildland Fire 18:857-864

Hood SM, Cluck DR, Smith SL, Ryan KC (2008) Using bark char codes to predict post-fire cambium mortality. Fire Ecol 4:57-73

Hood SM, Smith SL, Cluck DR (2010) Predicting mortality of five California conifers following wildfire. For Ecol Manage 260:750 762

Jackson JF, Adams DC, Jackson UB (1999) Allometry of constitutive defense: a model and a comparative test with tree bark and fire regime. Am Nat 153:614-632

Keeley JE, Zedler PH (1998) Evolution of life histories in Pinus. In: Richardson DM (ed) Ecology and biogeography of Pinus. Cambridge University Press, Cambridge, pp 219-250

Ordóñez JL, Retana J, Espelta J (2005) Effects of tree size, crown damage, and tree location on post-fire survival and cone production of Pinus nigra trees. For Ecol Manage 206:109-117 
Ordoñez JL, Molowny-Horas R, Retana J (2006) A model of the recruitment of Pinus nigra from unburned edges after large wildfires. Ecol Modell 197:405-417

Pausas JG, Llovet J, Rodrigo A, Vallejo R (2008) Are wildfires a disaster in the Mediterranean basin?-A review. Int J Wildland Fire 17:713-723

Peterson DL, Ryan KC (1986) Modeling postfire conifer mortality for long-range planning. Env Manage 10:797-808

Pimont F, Prodon R, Rigolot E (2011) Comparison of postfire mortality in endemic Corsican black pine (Pinus nigra ssp. laricio) and its direct competitor (Pinus pinaster). Ann For Sci 68:425-432

Retana J, Arnan X, Arianoutsou M, Barbati A, Kazanis D, Rodrigo A (2012) Post-fire management of non-serotinous pine forests. In: Moreira F, Arianoutsou M, Corona P, de las Heras J (eds). Postfire management and restoration of Southern European forests, managing forest ecosystems 24. Springer: New York. pp 151-170

Rodrigo A, Retana J, Picó X (2004) Direct regeneration is not the only response of Mediterranean forests to large fires. Ecol 85:716-729

Ryan KC (1982) Techniques for assessing fire damage to trees. In: Lotan J (ed). Proceedings of the symposium: fire, its field effects. Intermountain Fire Council, pp 1-11

Ryan KC (1998) Analysis of the relative value of morphological variables in predicting fire-caused tree mortality. In: Viegas DX (ed) Proc. 3rd Int. Conf. Forest Fire Research and 14th Fire and Forest Meteorology Conf. ADAI, Coimbra, pp 1511-1526

Ryan KC, Reinhardt ED (1988) Predicting post-fire mortality of seven western conifers. Can J For Res 18:1291-1297

Sieg C, McMillin J, Fowler J, Allen K, Negron J, Wadleigh L, Anhold J, Gibson K (2006) Best predictors for postfire mortality of ponderosa pine trees in the Intermountain West. For Sci 52:718-728

Tapias R, Gil L, Fuentes-Utrilla P, Pardos J (2001) Canopy seed banks in Mediterranean pines of south-eastern Spain: a comparison between Pinus halepensis Mill., P. pinaster Ait., P. nigra Arn., and $P$. pinea L. J Ecol 89:629-638

Tapias R, Climent J, Pardos J, Gil L (2004) Life histories of Mediterranean pines. Plant Ecol 171:53-68

Touchan R, Baisan C, Mitsopoulos I, Dimitrakopoulos A (2012) Fire history in European black pine (Pinus nigra Arn.) forests of the Valia Kalda, Pindus mountains, Greece. Tree-Ring Res 68:45-50

van Mantgem P, Schwarz M (2004) An experimental demonstration of stem damage as a predictor of fire-caused mortality for ponderosa pine. Can J For Res 34:1343-1347

Woolley T, Shaw DC, Ganio LM, Fitzgerald F (2012) A review of logistic regression models used to predict post-fire tree mortality of western North American conifers. Int J Wildland Fire 21:1-35 